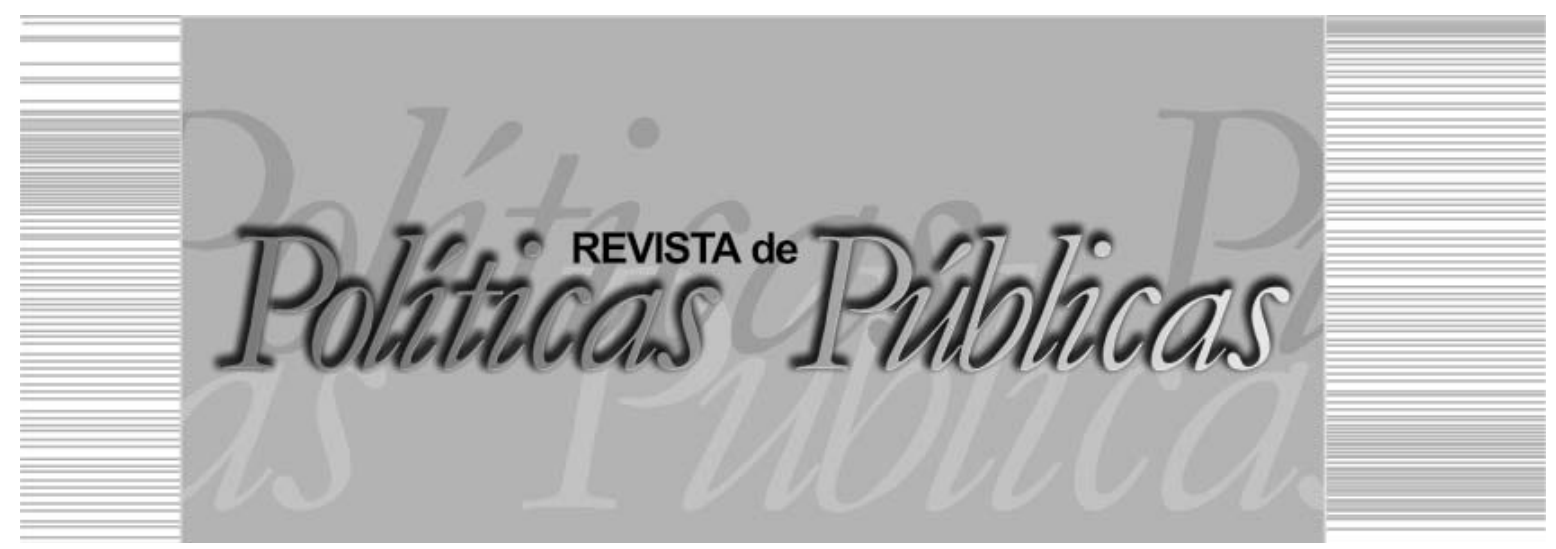

\title{
SEGURIDADE SOCIAL E PARTICIPAÇÃO: considerações sobre a política previdenciária no Brasil
}

\author{
Edivane de Jesus ${ }^{l}$ \\ Universidade Federal de Santa Catarina (UFSC) \\ Jorge Vasconcelos \\ Instituto Nacional do Seguro Social (INSS) 2
}

\section{Resumo}

O objetivo deste artigo é debater a participação social na seguridade brasileira e, de modo específico, na política de previdência, considerando o processo histórico de redemocratização do país e a realidade social atual. Por meio da análise de produções teóricas, legislações e dos espaços de controle social da seguridade, busca problematizar a ausência de mecanismos efetivos de participação na política de previdência social. Os resultados da pesquisa permitem apontar possíveis razões do cerceamento da democratização na política previdenciária, evidenciando a necessidade de construção da mesma por outras bases, em que a classe trabalhadora possa ter voz e protagonismo.

Palavras-chave: Redemocratização, seguridade social, Previdência Social, participação e controle social.

\footnotetext{
Assistente Social. Doutoranda do Programa de Pós-Graduação em Serviço Social (PPGSS) da Universidade Federal de Santa Catarina (UFSC). Assistente Social do Instituto Nacional do Seguro Social (INSS) de Santa Catarina. E-mail: edivanejesus@hotmail.com Universidade Federal de Santa Catarina - UFSC | Campus Universitário Prof. João David Ferreira Lima, Trindade, Florianópolis - SC | CEP: 88040-900

2 Assistente Social. Mestre em Serviço Social. Assistente Social do Instituto Nacional do Seguro Social (INSS). E-mail: j.og22@hotmail.com | Instituto Nacional do Seguro Social - INSS | Setor de Autarquias Sul Quadra 2 Bloco O BL O - Asa Sul, Brasília - DF | CEP: 70070-946
} 
SOCIAL PARTICIPATION AND SECURITY: considerations on the social security policy in Brazil

\begin{abstract}
The objective of this article is to discuss social participation in the Brazilian social insurance and, specifically, in security policy, considering the historical process of democratization of the country and the current social reality. Through the analysis of theoretical productions, laws and spaces for participation and social control of security, sought to problematize the absence of effective mechanisms of participation in social security policy. The search results may point out at the end of the article, possible reasons for the restriction of democratization in social security policy, emphasizing the need to build the same for other bases, in which the working class can have a voice and role.

Key words: Democratization, social insurance, Social Security, participation and social control.
\end{abstract}

\title{
1 INTRODUÇÃO
}

A sistematização proposta neste trabalho remete a um objetivo principal: debater a participação social na seguridade brasileira, em especial na política de previdência, considerando o processo histórico de redemocratização do país e a realidade social atual. Essa prerrogativa atende ao pressuposto central da investigação sob o enfoque dialético-materialista ${ }^{1}$, o qual possibilita situar e analisar os aspectos sociais em seu contraditório e complexo processo de produção e reprodução, frente aos múltiplos aspectos que os determinam, numa perspectiva estrutural, o que significa analisá-los inseridos na totalidade.

O interesse pela temática se dá em função da inserção profissional dos autores na política previdenciária brasileira, o que possibilitou conhecer as entranhas da política de Previdência Social e questionar a ausência de espaços ampliados de participação e deliberação na referida política.

Com a Constituição Federal (CF) de 1988, mediante a reivindicação dos movimentos sociais, criaram-se espaços de participação institucionalizada, que possibilitaram a participação da sociedade na gestão do Estado, instituindo dispositivos nas esferas públicas de âmbitos federal, estadual e municipal. A carta constitucional também instituiu o sistema de seguridade social, reorganizando as políticas de previdência, saúde e assistência social em uma nova 
estrutura, com novos princípios e diretrizes. No que diz respeito à organização de espaços de participação, em um primeiro momento a saúde, e, posteriormente, a assistência social, ainda que necessária a crítica sobre a qualidade e efetividade destes, organizaram espaços participativos por meio de conselhos e conferências. O mesmo não aconteceu com a Previdência Social. Apesar de o Conselho Nacional de Previdência Social (CNPS) ter sido instituído em 1991 e terem organizado conselhos estaduais/municipais e, depois, regionais, estes espaços não possuem caráter deliberativo, bem como também não conseguem assegurar uma representatividade da sociedade civil, ainda que formal. Neste sentido, interessa problematizar no presente artigo o porquê, tendo se passado 27 anos da promulgação da Constituição, a participação da sociedade civil ainda está por ser garantida na política previdenciária. Em face disso, no segundo item serão abordados pontos importantes do processo de redemocratização do país, pós-golpe militar de 1964, e os acontecimentos que culminaram na construção e promulgação da CF de 1988.

Na sequência, no terceiro item, são expostos alguns aspectos do processo de organização da participação no sistema de seguridade social desde a Carta Magna, com enfoque nas políticas de saúde e assistência, sinalizando os limites em que se inscreve o modelo de representação e participação adotado.

Por fim, buscar-se-á problematizar a ausência de mecanismos efetivos de participação, na Política de Previdência Social, sinalizando a necessidade da construção destes, tendo em vista a importância da participação democrática para a universalização desse direito.

\section{A TRANSIÇÃO DEMOCRÁTICA}

O golpe militar de abril de 1964 desempenhou na geopolítica mundial e no movimento de organização do capital um importante papel. Impediu, não a instalação de um regime comunista, conforme $\mathrm{o}$ argumento utilizado junto à população para justificar a tomada de poder pelos militares, mas sim a realização de reformas de base, de conteúdo nacionalista, que ameaçavam a conformação do capitalismo entre centro e periferia, contrariando os interesses imperialistas. O golpe teve, assim, o objetivo de assegurar, de acordo com Ianni (1984), que o país permanecesse na condição de economia de capitalismo dependente. 
De acordo com Fernandes (1986, p. 14), os impactos causados pelas proposições de João Goulart ensejaram o golpe de 1964, sob o aporte norte-americano e o slogan de proteção da ordem, da família, de preceitos religiosos, do desenvolvimento e da modernização. Para o autor, no entanto, a preocupação era sufocar e reprimir os "[...] dinamismos espontâneos da mudança social revolucionária."

\begin{abstract}
A consequência geral é que as forças da contra-revolucão tomam as aparências, o vocabulário e as posturas das forças da revolução, na ânsia de deslocá-las do endosso popular. E, através do estado e de todas as instituições chaves da Nação, realizam políticas de aceleração da acumulação capitalista (por sua própria essência anti-sociais e anti-nacionais) e de fusão programada às economias, aos sistemas de poder e às organizações ideológicas dos países centrais e de sua superpotência. (FERNANDES, 1986, p. 15).
\end{abstract}

Para Ianni (1984), o golpe militar configurou a tomada de poder por um novo e poderoso bloco, que atuava em nome dos interesses da burguesia. Os anos que seguiram foram marcados pela reorganização econômica/produtiva do país, que necessitava se adaptar à organização do capitalismo internacional, pelo cerceamento da liberdade de expressão e repressão de movimentos populares. De acordo com o autor, este contexto hostil agudizou contradições de classe e contribuiu para um processo de repolitização da classe operária, camponesa e de outros extratos de classe. Ressurgiram, assim, manifestações políticas e greves que, por sua vez, alçaram lideranças sociais e sindicais.

Com o passar dos anos, o bloco de poder que conduziu o período de ditadura entra em crise. Entre o emaranhado de fatores que desencadearam esta crise, Ianni (1984) lista: o descontentamento da burguesia nacional com o comprometimento do Estado com o grande capital estrangeiro, o aprofundamento dos protestos da classe trabalhadora contra a superexploração do seu trabalho, cada vez maior distanciamento da sociedade civil e Estado, corrupção, entre outras questões.

Na mesma direção, Fernandes (1986) sinaliza a possibilidade de analisar o processo de redemocratização do país, após o golpe militar de 1964, sob diferentes ângulos. Para o autor, a pressão e organização popular, diante das atrocidades cometidas e o cerceamento da liberdade, influíram diretamente no desgaste das estruturas do regime militar, mas não menos determinante foi a existência de uma crise interna. Fernandes (1986) aponta, neste sentido, a impotência 
deste regime em oferecer respostas às demandas da sociedade diante das transformações econômicas, sociais, culturais e na organização do Estado.

\begin{abstract}
A "crise da ditadura" coloca-nos diante de um processo histórico revelador: na América Latina, não são só as revoluções que são interrompidas. As contra-revolucões também. As classes burguesas dominantes são impotentes para conduzir as revoluções inerentes à transformação capitalista. Ameaçadas (ou supondo-se ameaçadas), elas recorrem ao seu braço armado, implantam uma ditadura civil militar e fazem a vitória pender para a contra-revolucão. Em seguida descobrem que os mesmos problemas que criavam desassossego e inquietação social, colocando as revoluções burguesas na ordem do dia, são arraigados e fortes demais para serem resolvidos dentro da ordem [...] (FERNANDES, 1986, p. 9, grifo do autor).
\end{abstract}

O fato é que, em função da grave crise interna, os próprios membros do bloco de poder que orquestram o golpe começaram a acreditar que a democracia deveria ser reestabelecida. Havia o entendimento, portanto, que esta estratégia, antes de se configurar como derrota, era um recuo necessário, para que não fosse preciso "[...] ceder nada de substancial aos trabalhadores." (IANNI, 1984, p. 111). Era preciso realizar a abertura democrática controlada e, nas palavras de Ianni (1984, p. 111), "[...] modificar algumas coisas para que nada se transforme."

De acordo com o autor supracitado, o bloco de poder que comandava a ditadura, opta assim, por realizar reformas sem profundidade, de modo a buscar a garantia "[...] das bases jurídico-políticas do poder burguês ditatorial ou, no mínimo, autoritário." (IANNI, 1984, p. 111), questão que fica evidente na reforma partidária realizada naquele momento. A resposta dada pela burguesia ao movimento crescente de organização do operariado, campesinato, funcionalismo, estudantes, intelectuais, entre outros, foram reformas de cima para baixo (IANNI, 1984).

Nesse viés, o processo de transição, de acordo com Fernandes (1989), é permeado por manobras que tinham por objetivo que o bloco de poder, hegemônico, continuasse presente sob o regime democrático. Esta foi a máxima que permeou todo o processo de construção da nova constituição.

Os limites e as formas de "transição", onde eles puderam ser manejados a partir de cima, são bem conhecidos e estão lapidarmente inscritos na forma adotada no Brasil: "transição lenta, gradual e 


\begin{abstract}
segura". Os militares continuavam no sistema compósito de poder, só que com menor visibilidade, e a democracia desencadeava-se como um processo político travado pelas classes dominantes (incluindo-se nessa categoria a burguesia internacional e os centros externos de poder) e por programas repressivos de dissuasão policial-militar, camuflados ou não, conforme as circunstâncias. O objetivo central não era a democracia e sua consolidação, mas a estabilidade política da ordem estabelecida, com todas as distorções e iniquidades econômicas e sociais que contivessem. (FERNANDES, 1989, p. 366, grifos do autor).
\end{abstract}

A constituinte, segundo Fernandes (1989)2 ${ }^{2}$, contava com um congresso de composição conservadora, sob a qual o governo buscou direcionar e ajustar aos seus interesses. Ainda que diante desta configuração desfavorável, este não foi um espaço homogêneo, sendo permeado de tensões e lutas. Assim, os movimentos organizados da sociedade civil tiveram papel fundamental na garantia de direitos individuais e coletivos e outras conquistas importantes na nova carta constitucional, que justamente por sua heterogeneidade e contradição foi nominada por Fernandes (1989) de colcha de retalhos.

\title{
3 A CONSTITUIÇÃO FEDERAL DE 1988 E A PARTICIPAÇÃO NA SEGURIDADE SOCIAL
}

A CF de 1988 foi construída no período de fevereiro de 1987 a setembro de 1988 por 559 congressistas, entre deputados e senadores, que compunham a Assembleia Nacional Constituinte. É a sétima Carta Constitucional na história do país, desde sua independência. Promulgada no dia 5 de outubro de 1988, ficou conhecida popularmente como Constituição Cidadã e marcou o período de redemocratização do país (BRASIL, 2005).

A nova carta constitucional garantiu direitos políticos e possibilitou avanços em relação aos direitos civis e sociais no país. Reestabeleceu eleições diretas para os cargos de Presidente da República, governadores e prefeitos municipais, garantiu o direito ao voto aos analfabetos e decretou o fim da censura institucionalizada. Apesar de ter trazido a possibilidade de socialização da política, em função do seu processo de construção, que conforme já discorremos, seguiu uma linha de continuidade e não de ruptura com o regime anterior, a constituição não foi suficiente para garantir a socialização do poder político. 
No entanto, desde a promulgação da nova Constituição, a expressão participação social é constantemente utilizada no âmbito social, com sentidos e interesses distintos, permeando práticas de instituições públicas e, praticamente, todas as políticas sociais e programas de governo. Embora tenham sido criados espaços de participação institucionalizada, especialmente por meio dos conselhos e conferências, é necessária a problematização do modelo participativo estabelecido após a Carta Magna.

Assim, a constituição de arcabouços de representação fez com que fossem socialmente estabelecidas compreensões equivocadas de democracia, pautadas nas obrigatoriedades da realização de procedimentos eleitorais (expresso na ideia do voto útil) e nas garantias de igualdade, liberdade e participação no campo formal. Obviamente, estas prerrogativas estão distantes de serem consideradas suficientes a um processo efetivo de participação popular. Conforme sinaliza Moroni, (2009, p. 108):

Reduzir a democracia e a participação política apenas aos procedimentos eleitorais atende aos interesses das elites políticas e econômicas, pois abafam a voz e as demandas dos dominados. O discurso ideológico que dá sustentação a esta concepção de democracia é que todos têm as mesmas oportunidades e de que desigualdades entre as pessoas têm origem nas diferentes capacidades individuais ou depende de sorte.

O sistema representativo republicano moderno, de acordo com Vieira (2006), tem suas bases no direito liberal e na economia capitalista. Faz, portanto, parte de uma totalidade articulada, em que partidos políticos são considerados como os únicos atores legítimos, o que em grande medida, tem concorrido para a "[...] usurpação da soberania dos representados.” (VIEIRA, 2006, p. 112).

De acordo com Raichelis (2006), as práticas dos conselhos, em distintas políticas e níveis de governo, revelam o controle do Estado sobre a concepção, organização e implementação das políticas sociais, bem como espaços e processos burocratizados, situações de cooptação e rotineirização do seu funcionamento. Para a autora, esta centralização de poder nas mãos do executivo, muitas vezes, fragiliza e fere a autonomia dos conselhos, utilizando-se de mecanismos para neutralizar ou mesmo prejudicar suas ações e decisões. Muitos são os exemplos desta interferência no funcionamento dos conselhos, entre eles Raichelis (2006) sinaliza a manipulação de informações ou simplesmente sua sonegação; a nomeação de representantes 
da sociedade civil sem que se tenha realizado processo eleitoral que garanta sua legitimidade; cooptação de membros dos conselhos, entre outros.

Ao que se refere à sociedade civil, Raichelis (2006) sinaliza também a necessidade de repensar a dinâmica da representação e participação no âmbito dos conselhos. Pontua a primordialidade de qualificar esta participação, no intuito de que ela tenha por objetivo a defesa de pautas coletivas em detrimento de questões pontuais e demandas corporativistas.

Em relação ao sistema de seguridade social, instituído pela CF de 1988, composto pelas políticas de saúde, assistência social e previdência, a Carta Magna traz no seu artigo 193 (sobre o título VIII - da ordem social), que trata dos princípios gerais da Seguridade Social, de forma mais explícita a participação, como sendo direito de trabalhadores, empresários e aposentados (BRASIL, 2005).

Acerca da política de saúde, o texto constitucional faz menção à participação da comunidade. A política de saúde é pioneira nesta organização e já contava com um movimento de organização popular consistente, anterior a Constituinte, que foi decisivo para que adquirisse o status de direito universal e a garantia do atendimento integral, por meio da instituição do Sistema Único de Saúde - SUS. Em que pese os problemas já sinalizados, em relação à participação social institucionalizada pós 1988, em dezembro de 2015 ocorreu a $15^{\mathrm{a}}$ Conferência Nacional de Saúde, que procedeu às etapas de conferências municipais e estaduais. Também estão instituídos, em todos os municípios e Estados, Conselhos de Saúde, organicamente interligados com o Conselho Nacional de Saúde (CNS) e responsáveis pela gestão do fundo da política.

Esse processo de organização veio bem mais tarde para a política de assistência social. Muito embora esta tenha adquirido o status de política pública na Carta Constitucional, a Lei Orgânica da Assistência Social é promulgada apenas em 1993 e traz algumas diretrizes em relação à organização de conselhos e conferências. Mas é só a partir de 2004, com a Norma Operacional Básica (NOB), que a assistência social passa a efetivamente construir as estruturas necessárias para a descentralização da política e recursos, bem como a criação desses espaços de participação. Também ocorreu em 2015 a X Conferência Nacional de Assistência Social, última etapa de con- 
SEGURIDADE SOCIAL E PARTICIPAÇÃO: considerações sobre

a política previdenciária no Brasil

sulta e deliberação, após a realização das conferências municipais e estaduais que ocorreram em todo Brasil.

\section{A PARTICIPAÇÃO SOCIAL NA POLÍTICA DE PREVIDÊNCIA}

Dentre as políticas que compõem a seguridade social, a previdência social tem seguido caminho diferente em relação à institucionalização da participação. A Lei Complementar n ${ }^{\circ} 8213$, de 24 de julho de 1991 que instituiu os Planos de Benefícios da Previdência Social é a mesma que instituiu o CNPS e o Conselho Nacional de Seguridade $\mathrm{Social}^{3}$ (CNSS). O CNPS teve sua reunião inaugural em 29 de agosto de 1991, tendo seu Regimento Interno aprovado através da Resolução CNPS no 1 , de 22 de julho de 1992. (DELGADO et al., 2002). ${ }^{4}$

Em 2003, o conselho passa por uma reformulação que mantém as estruturas organizativas centrais do CNPS, mas por meio do Decreto $\mathrm{n}^{\mathrm{0}} 4.874$, de 11 de novembro de 2003 extingue os Conselhos Estaduais e Municipais de Previdência Social ${ }^{5}$ e cria os Conselhos de Previdência Social (CPS). Esses, nesse momento, se constituíam em unidades descentralizadas do CNPS e, embora vinculadas ao MPS, eram organizados no âmbito das gerências executivas do Instituto Nacional de Seguro Social (INSS) ${ }^{6}$.

Cinco anos após sua criação, a Resolução $\mathrm{n}^{0} 1.304$, de 10 de dezembro de 2008 do CNPS, institui o Regimento Interno dos CPS. Segundo este mesmo decreto, os conselhos têm caráter consultivo e de assessoria, e são compostos de dez conselheiros: quatro representantes do governo; dois representantes dos trabalhadores; dois dos empregadores e dois dos aposentados e pensionistas. Essa mesma normativa reconhece nas reuniões mensais ou bimestrais, o convite regular a observadores (com direito a voz) e estabelece que esses devam ser: um representante da Receita Federal; um gerente local da DATAPREV ${ }^{7}$; e um representante da Federação Brasileira de Bancos (FEBRABAN), desde que esses já não componham titularidade ou suplência do conselho.

Por essa mesma normativa, os CPS necessariamente serão presididos pelo Gerente Executivo do INSS e, na ausência deste, pelo representante do Governo Federal com o mais alto cargo na hierarquia na Gerência Executiva, seja ele qual for. Já os representantes da sociedade civil são indicados por centrais sindicais, entidades 
sindicais, associações sindicais e/ou associações representativas. O mesmo regimento, no art. 12, recomenda tratar, pelo menos uma vez ao ano, dos seguintes pontos:

I - plano de ação da Gerência Executiva e planejamento para o período subsequente;

II - cobertura previdenciária e política local de inclusão previdenciária;

III - indicadores de atendimento e propostas de melhoria do atendimento nas agências locais;

IV - benefícios por incapacidade e propostas relacionadas com a prevenção de acidentes e doenças ocupacionais;

$\mathrm{V}$ - resultados da atuação da Procuradoria e propostas para redução de ações;

VI - reabilitação profissional na Gerência Executiva e propostas de ampliação e melhoria do atendimento;

VII - atuação da perícia médica na Gerência Executiva;

VIII - recursos humanos na Gerência Executiva: necessidade, políticas de qualificação e capacitação;

IX - atuação da Secretaria da Receita Federal do Brasil na área geográfica da Gerência Executiva; e

$\mathrm{X}$ - atuação da DATAPREV na área geográfica da Gerência Executiva. (BRASIL, 2008, p. 3).

Em seu fundamento, os conselhos de política foram pensados para serem órgãos paritários, de democracia participativa, onde se discute, elabora e fiscaliza as políticas sociais na perspectiva da universalização de direitos e pelo viés do Estado, orientados não somente por uma democracia participativa, mas pela construção de uma democracia de massas. (BRAVO, 2009). No entanto, não é esta a realidade que se observa na política de previdência social brasileira.

Através da Medida Provisória (MP) $\mathrm{n}^{0} 726$, de 12 de maio de 2016, o CNPS torna a ser reformulado, tendo o seu nome alterado para Conselho Nacional de Previdência (CNP) e passando a estar vinculado ao Ministério da Fazenda. Pela primeira vez o Conselho compõe estrutura ministerial diferente do INSS, o qual passou a compor o Ministério do Desenvolvimento Social e Agrário (MDSA) $)^{8}$ 
Apesar das recentes mudanças na estrutura, até o momento o Estatuto do Conselho permanece inalterado, continua restringindo que um dos seis representantes da sociedade civil possa presidi-lo e que os usuários da política possam se representar individualmente. Não são realizadas conferências, de modo que a população em geral tenha espaços de discussão e deliberação dos rumos da política e de seu financiamento.

Tratando-se mais especificamente dos representantes dos trabalhadores, ressalta-se que os membros são indicação das federações, centrais sindicais e entidades sindicais. (BRASIL, 2003). Deixam de estar contemplados e representados, portanto, os movimentos sociais, os trabalhadores informais, os desempregados, extratos da classe trabalhadora, os quais sofrem diretamente os impactos das interferências na política previdenciária.

As entidades representativas, por sua vez, deveriam ter uma base de representatividade e um histórico de organização e dinâmica de funcionamento democrático, com vistas a fortalecer as lutas coletivas, denunciando as tentativas de corrosão dos direitos dos trabalhadores, o que nem sempre ocorre. A participação dos conselheiros passa por uma crise de representatividade, diante de suas categorias. Considerando as composições que os últimos governos têm realizado e o processo de cooptação de parte das organizações sindicais e movimentos sociais, cada vez mais, esta questão tem estado mais evidente. Isso porque, nem sempre, os representantes dos trabalhadores e segurados da previdência estão a serviço dos interesses de classe, o que impacta diretamente na defesa e na luta por ampliação de direitos.

Delgado e outros (2002) produziram pesquisa sobre a formação e as produções normativas do CNPS, através da análise documental e entrevistas com conselheiros e ex-conselheiros do CNPS. $O$ estudo revelou a total falta de autonomia destes espaços, que desde as suas formações serviram muito mais de locais de legitimação das políticas de governo, do que espaços de caráter democrático e descentralizado da administração, mediante gestão paritária.

Além da ausência de assessoria técnica aos conselheiros, as resoluções, moções e recomendações emitidas pelo CNPS necessitam de ato administrativo correspondente que as legitimem e viabilizem, o que, segundo Delgado e outros (2002), historicamente não ocorre pela dificuldade de interlocução com o Congresso e, especial- 
mente, pelos embargos por parte do governo federal. Nesse aspecto, é interessante recordar que tanto as contrarreformas instituídas pela $\mathrm{EC} \mathrm{n}^{\circ} 20 / 1998$, quanto mais recentemente nas alterações promovidas pelas MP's n $n^{\circ} 664$ e $n^{\circ} 665$, de 30 de dezembro de 2014, convertidas nas Leis $\mathrm{n}^{\circ} 13.183$, de 4 de novembro de 2015 e n $^{\circ} 13.135$, de 17 de junho de 2015, foram elaboradas em nível de governo, desconsiderando os conselhos como órgãos democráticos e deliberativos de tomada de decisões e de participação da população.

Ao analisar os processos de (contra) reforma da previdência no Cone Sul, num estudo comparativo entre Brasil, Argentina e Uruguai, Stephen J. Kay (2003) refere que os processos de participação popular nos anos 1990 tiveram papel determinante nas perspectivas e no grau das reformas nesses sistemas de previdência. No caso uruguaio, houve três ocasiões em que plebiscitos decidiram o caráter público do sistema de previdência. Em 1989, um plebiscito mobilizado pelos aposentados e pensionistas propôs uma emenda constitucional que vinculou os proventos previdenciários ao salário médio. O governo propôs um plebiscito em 1994, com medidas de privatização. Foi derrotado. Nesse mesmo ano, um plebiscito organizado pelos aposentados e pensionistas rechaçou cortes no projeto orçamentário dos benefícios.

Deste modo, entende-se que garantir os fundamentos da paridade e da democracia participativa passa por garantir a direção crítica das discussões e elaborações realizadas no âmbito dos Conselhos de Previdência (CPS/CNP), bem como este se constitua enquanto espaço de deliberação. Nesta direção, o caráter fiscalizatório pressupõe o controle democrático da elaboração, efetivação e avaliação da política previdenciária, bem como a sua organização e destinação orçamentária.

Logo, a extinção dos Conselhos Municipais e Estaduais de Previdência Social, que foram substituídos pelos CPS e a forma de organização nas gerências executivas, tornam-se contrárias à perspectiva universalista e participativa do controle social. Os conselhos descentralizados além de possibilitar uma maior participação da população usuária nas discussões relativas às temáticas previdenciárias serviam como instrumento de controle social dos gastos públicos e de ampliação de direitos. A atual subdivisão em CPS dificulta a participação dos trabalhadores e distancia as discussões e o controle social das Agências da Previdência Social, porta de entrada e de acesso 
aos benefícios previdenciários. A dissociação ministerial do CNP e do INSS (porta de entrada do reconhecimento do direito previdenciário), e a exclusão do nome social do Conselho vão além de uma mera reforma administrativa na busca pela eficiência. Representam a intencionalidade, que aponta para o reforço dos mecanismos excludentes de participação.

Muito embora a participação social não possa se resumir ao espaço dos conselhos e conferências, esta é claramente insuficiente, tampouco estes devem se configurar apenas como espaços de legitimação de decisões. Ao contrário, é fundamental que sejam repensados enquanto instrumentos de discussão, construção, denúncia e controle social. No caso da previdência, no atual momento político do país, estes instrumentos precisam ocupar-se de discussões acerca das macrorientações político-econômicas, e da proposta de (contra)reforma da previdência, que está sendo encaminhada ainda este ano, ao Congresso Nacional. Esta atual proposta tange a sete eixos: 1-Financiamento da Previdência Social: receitas, renúncias e recuperação de créditos; 2-Demografia e idade mínima das aposentadorias; 3-Diferença de regras entre homens e mulheres; 4-Regras das pensões por morte; 5-Previdência rural: financiamento e regras de acesso; 6-Regimes Próprios de Previdência; e 7-Convergência dos sistemas previdenciários. Tais medidas, bem como o debate sobre o orçamento desta política, devem ser submetidas à apreciação dos que sofrerão seus impactos: o conjunto da classe trabalhadora.

\section{CONCLUSÃO}

Uma das dificuldades na construção deste trabalho foi o fato de existirem poucos referenciais teóricos no que tange à temática da participação na política de previdência social. Encontramos um material considerável sobre o movimento de organização e conselhos na política de saúde e uma produção em crescimento sobre o tema na política de assistência social, mas apenas um referencial específico sobre a participação social na política previdenciária. Sem maiores pretensões, arriscamos a hipótese de que isso se dá pelo fato de que estudar a previdência é tarefa árdua. Trata-se de uma política extremamente hierarquizada, que impõe inúmeras barreiras para o acesso a dados e informações, cujos números são constantemente manipulados e envolta em uma série de interesses obscuros. 
Em relação à participação, no campo da denúncia, cabe sinalizar que os elementos aos quais se teve acesso evidenciam que, contrariando preceitos constitucionais, a participação nesta política é pró-forma. É a política pública a que são destinados o maior montante de recursos no país. No ano de 2014, 21,76\% (FATTORELLI; ÁVILA, 2015) do orçamento brasileiro executado, aproximadamente 500 bilhões, foi destinado ao custeio da previdência. Consiste em um dos maiores regimes de previdência pública do mundo, que cobre atualmente cerca de $60 \%$ da população economicamente ativa do Brasil, com imensa arrecadação e que movimenta a economia de estados e municípios. Em uma sociedade que, de acordo Moroni (2009), não foram criados mecanismos de participação popular, em relação à política econômica, e diretrizes ao modelo de desenvolvimento, parece óbvio que não exista o interesse em debater e democratizar este orçamento pelo viés da participação.

Historicamente, o fundo público da seguridade social, responsável pelos recursos destinados à previdência, é saqueado pelo Estado Brasileiro. Nos dados de 2014, este fundo, frequentemente acusado pelo governo de desestabilizar as contas públicas, devido ao pagamento dos benefícios previdenciários, apresentou superávit de R\$ 54 bilhões. (ASSOCIAÇÃO NACIONAL DOS AUDITORES FISCAIS DA RECEITA FEDERAL DO BRASIL, 2015) Desde 1994, a esfera governamental desvia recursos do fundo público da seguridade social, que tem saldo positivo, para injetá-los em outras rubricas, especialmente no pagamento dos juros da dívida. Este desvio torna-se operação legal, por meio da Desvinculação das Receitas da União (DRU), mecanismo criado durante o Governo Fernando Henrique Cardoso (FHC), e prorrogado pelo Governo da Presidente Dilma 9 . Pela proposta de 2011, por meio desta prerrogativa de lei, cerca de $20 \%$ dos recursos destinados ao sistema de Seguridade Social são transformados em superávit primário, deixam de compor o orçamento da seguridade social e de possibilitar a ampliação de benefícios e serviços.

Uma política com esse volume de recursos, oriundos de contribuições sociais do conjunto da classe trabalhadora, é ferramenta funcional aos interesses de mercado, não podendo (aos olhos da classe hegemônica) estar sobre o controle paritário, democrático e transparente da classe que vende sua própria força de trabalho. 
Portanto, a partir do entendimento deste processo contraditório dos desafios a enfrentar e das inúmeras possibilidades, entende-se como urgente a reivindicação, pelos setores mais progressistas da sociedade, da democratização dos espaços de participação na política previdenciária. Faz-se necessário ressignificar e construir a participação no âmbito da política por outras bases, em que a classe trabalhadora, que é quem financia esta política, possa ter voz e protagonismo na perspectiva da construção de outro padrão de sociabilidade, em que a democracia participativa sirva a todos e não somente a alguns.

\section{REFERÊNCIAS}

ASSOCIAÇÃO NACIONAL DOS AUDITORES FISCAIS DA RECEITA FEDERAL DO BRASIL. Análise da Seguridade Social 2014. Brasília, DF, 2015. Disponível em: $<$ http://www.anfip.org. br/publicacoes/20150713162859 Analise-da-Seguridade-Social2014_13-07-2015_20150710-Anlise-Seguridade-2014-Verso-Final. pdf $>$. Acesso em: $\overline{3} 0$ abr. 2015

BRASIL. Conselho Nacional da Previdência Social. Resolução ${ }^{\circ}$ 1.304, de 10 de dezembro de 2008. Institui o Regimento Interno dos CPS. Diário Oficial da União, Brasília, DF, 2008. Disponível em:<http://www010.dataprev.gov.br/sislex/paginas/72/MPSCNPS/2009/1304.htm>. Acesso em: 30 nov. 2015.

Constituição da República Federativa Brasileira de 1988. 35. ed. atual. e ampl. São Paulo: Saraiva 2005.

Presidência da República. Decreto $\mathrm{n}^{\circ} 4.874$, de 11 de novembro de 2003. Acresce artigo ao Regulamento da Previdência Social, aprovado pelo Decreto n⿳0 3.048 , de 6 de maio de 1999. Diário Oficial da União, Brasília, DF, 2003. Disponível em: $<$ http://www. planalto.gov.br/ccivil_03/decreto/2003/d4874.htm> Acesso em: 30 nov. 2015.

Lei no 8.213 , de 24 de julho de 1991. Dispõe

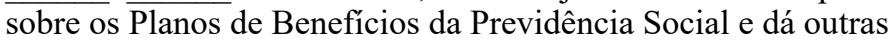
providências. Diário Oficial da União, Brasília, DF, 1991. Disponível em:<http://www.planalto.gov.br/ccivil_03/leis/L8213 cons.htm>. Acesso em: 20 nov. 2015.

BRAVO, M. I. de S. O trabalho do assistente social nas instâncias públicas de controle democrático. In: CONSELHO FEDERAL DE SERVIÇO SOCIAL. Direitos sociais e competências profissionais. 
Brasília, DF, 2009. p. 411-428. Disponível em:<http://www.cressrn. org.br/files/arquivos/9IN2mnNP98m5WmPos413.pdf $>$ Acesso em: 25 nov. 2015.

DELGADO, G. C. et al. A participação social na gestão pública: avaliação da experiência do Conselho Nacional de Previdência Social 1991/2000. Texto para Discussão, Brasília, DF, n. 909, 2002.

FATTORELLI, M. L.; ÁVILA, R. Gastos com a dívida pública em 2014 superaram $45 \%$ do orçamento federal executado. Auditoria Cidadã da Dívida, Brasília, DF, 2015. Disponível em: $<$ http://www. auditoriacidada.org.br/e-por-direitos-auditoria-da-divida-ja-confira-ografico-do-orcamento-de-2012/>. Acesso em: 30 abr. 2016.

FERNANDES, F. A constituição inacabada: vias históricas e significado político. São Paulo: Estação Liberdade, 1989.

. Nova república? 2. ed. Rio de Janeiro: Jorge Zahar, 1986.

IANNI, O. O ciclo da revolução burguesa. Petrópolis: Vozes, 1984.

KAY, S. J. Privatizações inesperadas: política e reforma da previdência social no Cone Sul. In: COELHO, V. S. P. (Org). A reforma da previdência social na américa Latina. Rio de Janeiro: Editora FGV, 2003.

MARX, K. A Ideologia alemã: Capítulo I. Tradução Silvio Donizete Chagas. São Paulo: Centauro, 2002.

MORONI, J. A. O direito à participação no Governo Lula. In: AVRITZER, L. experiências nacionais de participação social. São Paulo: Cortez, 2009.

NOVACK, G. Introdução à Lógica Marxista. São Paulo: Instituto José Luis e Rosa e Sudermann, 2005.

RAICHELIS, R. Democratizar a gestão das políticas sociais: um desafio a ser enfrentado pela Sociedade Civil. In: MOTA, M. E. et al. Serviço Social e Saúde: formação e trabalho profissional. São Paulo: OPAS, OMS, Cortez, 2006.

VIEIRA, L. V. A democracia com pés de barro. Recife: Editora Universitária da UFPE, 2006.

\section{NOTAS:}

1 Segundo Novack (2005), o marxismo tem como base filosófica o materialismo, entendido como corrente da filosofia, cujo método básico é a lógica dialética. O materialismo filosófico, dessa forma, opõe-se ao idealismo, e a lógica dialética distingue-se, nos mesmos termos, da lógica formal. 


\title{
SEGURIDADE SOCIAL E PARTICIPAÇÃO: considerações sobre
}

\author{
a política previdenciária no Brasil
}

“As premissas com que começamos não são arbitrárias, não são dogmas. São premissas reais, e delas só na imaginação se pode abstrair. São os indivíduos reais, a sua ação e as suas contradições materiais de vida, tanto as que encontraram como as que produziram pela sua própria ação. Estas premissas são, portanto, constatáveis de um modo puramente empírico." (MARX, 2002, p. 14)

2 O autor, em 1986, foi eleito deputado constituinte pelo Partido dos Trabalhadores (PT) e participou da elaboração da Constituição de 1988.

3 Extinto pela MP nº 1799-5, de 13 de maio de 1999, em 1999.

4 Embora, como já referido, a Constituição após 1988, tenha reconhecido (re)criação dos conselhos de previdência, estes já existiam enquanto Conselhos Corporativos Tripartites (governo, trabalhadores e empresários), dentro das estruturas do Instituto de Aposentadorias e Pensões (IAPs), praticamente extinto nos anos 50.

5 Em 1993 foram criados os conselhos descentralizados (estadual e municipal) de previdência. E em 1999 foram extintos por medida provisória (MP nº1799-5/1999), sob a alegação de que tais, não correspondiam às expectativas de descentralização.

6 Atualmente o INSS possui 104 gerências executivas, espalhadas por todo território nacional.

7 Órgão que após o desmonte do Ministério da Previdência Social, passou a ser vinculado ao Ministério do Tesouro Nacional e é responsável pela gestão da plataforma tecnológica informatizada deste e de outros Ministérios.

8 No momento em que esse artigo é inscrito, a presidenta eleita Dilma Rousseff encontra-se afastada, respondendo por denúncia de crime fiscal. O governo interino vem promovendo uma série de mudanças que vêm causando incertezas quanto à estrutura das políticas públicas e às perspectivas de gestão das mesmas.

9 Até o fechamento deste artigo tinha sido aprovado em primeiro turno pelo congresso, uma Proposta de Emenda Constitucional (PEC) encaminhada em 2015, pela então presidenta em exercício, de prorrogação da DRU até 2023. Pela essa, o percentual a ser desvinculado é alterado de $20 \%$ para $30 \%$. Medida retroativa a janeiro do presente ano. A mesma PEC também abre essa possibilidade de desvinculação por parte dos Estados, municípios e o distrito federal. 
